\title{
The impact of a standardized order set for the management of non-hip fragility fractures in a Fracture Liaison Service
}

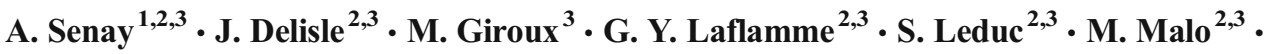 \\ H. Nguyen ${ }^{3}$ • P. Ranger ${ }^{2,3}$ - J. C. Fernandes ${ }^{1,2,3}$
}

Received: 30 November 2015 / Accepted: 13 June 2016 /Published online: 1 July 2016

(C) The Author(s) 2016. This article is published with open access at Springerlink.com

\begin{abstract}
Summary We analysed the impact of a standardized order set empowering staff nurses to independently manage a Fracture Liaison Service over a 9-month period. Nurses identified between 30 and $70 \%$ of non-hip fragility fractures to the unit in charge of management over time. The latter managed $58 \%$ of referred patients.

Introduction The main goal of this study was to evaluate the impact of a standardized order set empowering nurses to independently manage a fracture liaison service (FLS).

Methods Since November 2014, an order set allowed nurses of a Montreal hospital, Quebec, Canada to entirely manage an FLS on their own. Nurses followed an 6-h training program on-site. Emergency department (ED) and orthopaedic outpatient clinic (OC) nurses identified non-hip fragility fractures. Medical day treatment unit (MDTU) nurses were in charge of the management (investigation and treatment initiation). The list of patients, 50 years and older, with a fracture were retrieved for the period of November 2014 to July 2015. Performance was assessed with the rate of identification over time and the rate of management of non-hip fragility fractures.
\end{abstract}

J. C. Fernandes

julio.c.fernandes@umontreal.ca

1 Université de Montréal, 2900 bl. Edouard-Montpetit, Montreal, Quebec H3T 1J4, Canada

2 Centre de Recherche de l' Hôpital du Sacré Coeur de Montréal, Hôpital du Sacré-Cour de Montréal, 5400 bl. Gouin ouest, Montreal, Quebec H4J 1C5, Canada

3 Hôpital Jean-Talon, 1385 rue Jean-Talon est, Montreal, Quebec H2E 1S6, Canada
Results Over the 9-month period, 346 patients of $\geq 50$ years old were seen for a fracture, of which 190 met fragility criteria (excluding hip fractures). A sinusoid pattern of rates of identification between $30-70 \%$ was observed over time. An average proportion of $58.1 \%$ of fracture patients were managed by MDTU nurses.

Conclusions A standardized order set legally allowing nurses to manage an FLS led to identification rates varying from 30 $70 \%$ and a management rate close to $60 \%$ for referred patients over a 9-month period, which largely exceeds that of standard care. Identification was mostly compromised by difficulty integrating the order set into routine practice. Enforcement of the hospital policy on fragility fractures could help yield efficiency of identification of osteoporosis-related fractures by the staff.

Keywords Fracture liaison service · Fragility fracture Identification · Management · Order set · Osteoporosis

\section{Introduction}

The loss of bone mass identified as osteoporosis or osteopenia can lead to osteoporosis-related fractures, namely fragility fractures [1]. Each year in Canada, 30,000 individuals sustain a hip fracture, which is associated with high morbidity and high mortality [2-5]. Moreover, the majority of patients with a hip fracture report at least one previous fragility fracture [6]. The treatment of such major events entails costs as high as $\$ 20,000$ per hospitalization, excluding associated long-term care expenses [7]. This human and financial burden is no longer acceptable since effective drug regimens can significantly reduce the risk of subsequent fractures [7-11]. These facts have raised awareness from the health professional community to mobilize and alleviate the care gap in osteoporosis 
[12]. The preferred model of secondary prevention for best results is known as the fracture liaison service (FLS), and its implementation is now recommended by many health organizations and societies [13-15].

Since 2010, a 4iFLS was implemented for research purposes in two hospitals of Montreal, Canada. The "4i" model stands for (1) identification of patients with fragility fractures, (2) investigation for bone fragility, (3) initiation of treatment and (4) integration of follow-up. Our orthopaedic team has recently assessed the role of nurses as independent case managers of an FLS [16]. Nurses were found to have the necessary skills and competence to independently provide safe and efficient care to patients within a program for the prevention of subsequent fractures.

Following these optimistic results, and for this scenario to become the norm, we needed our FLS guidelines to become best practice through an official and instituted medical order. Thus, our International Osteoporosis Foundation (IOF) Gold Level FLS (Lucky Bone ${ }^{\mathrm{TM}}$ ) program was expanded to an entire hospital through an order set $[13,14]$. Standardized order sets have demonstrated to have a positive impact on following healthcare guidelines and improving best clinical practices for various diseases or behaviours [17]. We used the Quebec civil code's Nurses Act in Canada, by law 90, article 36.1 of division VIII- "Practice of the profession states that nurses can prescribe diagnostic examination, medications/others substances and medical treatment" to legally allow nurses to prescribe drug therapy in order to apply the second $i$ and third $i$ of our FLS [18]. We hypothesized that standardized clinical guidelines within an order set would make it possible to implement our FLS with nurses as its stakeholders, thus improving fragility fracture patient's management. This paper presents the impact of the first standardized nurse-led order set issued for the management of fragility fractures in Canada.

\section{Methods}

\section{FLS management}

Effective on February 2014, an order set instituted in a hospital in Montreal, Quebec, Canada, legally allowed nurses with appropriate training to (1) identify fragility fractures, (2) refer patients to a special unit in charge of management, (3) screen for bone fragility with serum testing and bone densitometry, (4) prescribe a drug regimen for the prevention of subsequent fractures and (5) communicate with primary care physicians (PCPs) to transmit results. The integration of patients to follow-up (fourth i) to monitor patients for adherence, and persistence is being developed to become the role of a dedicated FLS nurse, a nurse practitioner or the PCP himself. They were to apply the FLS guidelines based on those developed by Osteoporosis Canada (OC) [19]. A fragility fracture was defined as a fracture that occurred spontaneously or sustained from a minor trauma (a fall from standing height, sitting position, horizontal positioning, from one to three steps) [20]. Fracture sites included the following: vertebrae, sternum, sacrum, wrist, forearm, clavicle, scapula, humerus, ribs, ankle, femur, tibia/fibula, hip and pelvis. Patients presenting with an open, traumatic or pathological fracture (positive monoclonal band, spreading cancer, multiple myeloma), neoplasia and pregnant/breastfeeding women were excluded.

The main tasks were to (1) identify patients aged 50 years or older with a fracture suspicious of fragility; (2) collect data on patients to identify clinical risk factors (demographics, PCP, exercise, alcohol intake, smoking habits, calcium intake, diet, medication, medical history) and conduct serum screening (total blood count, creatinine, thyroid stimulating hormone, parathyroid hormone, calcium, protein electrophoresis, C-reactive protein, alkaline phosphatase, 25-hydroxy vitamin D, osteocalcin, C-telopeptide), bone screening assessment (DXA) and estimate fracture risk using the FRAX tool [21]; (3) refer patients to a specialist if already taking an antiresorptive agent for osteoporosis for a period of 12 months or more before sustaining the index fracture (treatment failure) or patients under glucocorticoids therapy; (4) prescribe alendronate ( $70 \mathrm{mg}$ po $1 / 7$ days) or risedronate (35 $\mathrm{mg}$ po $1 /$ 7 days) with supplements of calcium carbonate $500 \mathrm{mg}$ (DIE or BID depending on calcium intake) and vitamin D3 10,000 ui/week and (5) refer patients with a contraindication to oral anti-resorptive agents or abnormal screening (for example a monoclonal band) or adverse effects to internal medicine. Non-referred patients automatically received a prescription for an anti-resorptive agent as secondary prevention. Treatment was initiated in patients considered at high and moderate risk of subsequent fragility fracture as recommended by OC guidelines. If screening results showed a low level of risk, treatment was stopped.

The three first mandates of a 4iFLS were allocated to specific departments to maximize the program's effectiveness, the fourth i for integration is still in development (Fig. 1). Nurses on the first line of care (emergency department-ED) were able to identify patients of 50 years or older, suspicious of bone fragility (first i). They referred patients to the medical day treatment unit (MDTU), where investigations (second i) and initiation of treatment (third i) were performed. Nurses of the orthopaedic outpatient clinic (OC) were also trained to screen for patients with a fracture meeting the criteria of fragility, so we were able to identify patients that were not in the ED. The MDTU nurses scheduled appointments with referred patients from the ED or the $\mathrm{OC}$ to initiate management. The integration of the patient into a follow up was temporarily performed by the FLS research coordinator with a telephone interview at 3 and 12 months after the MDTU visit.

The training of MDTU nurses consisted in a 6-h theoretical teaching involved eight modules: osteoporosis, diagnosis, 


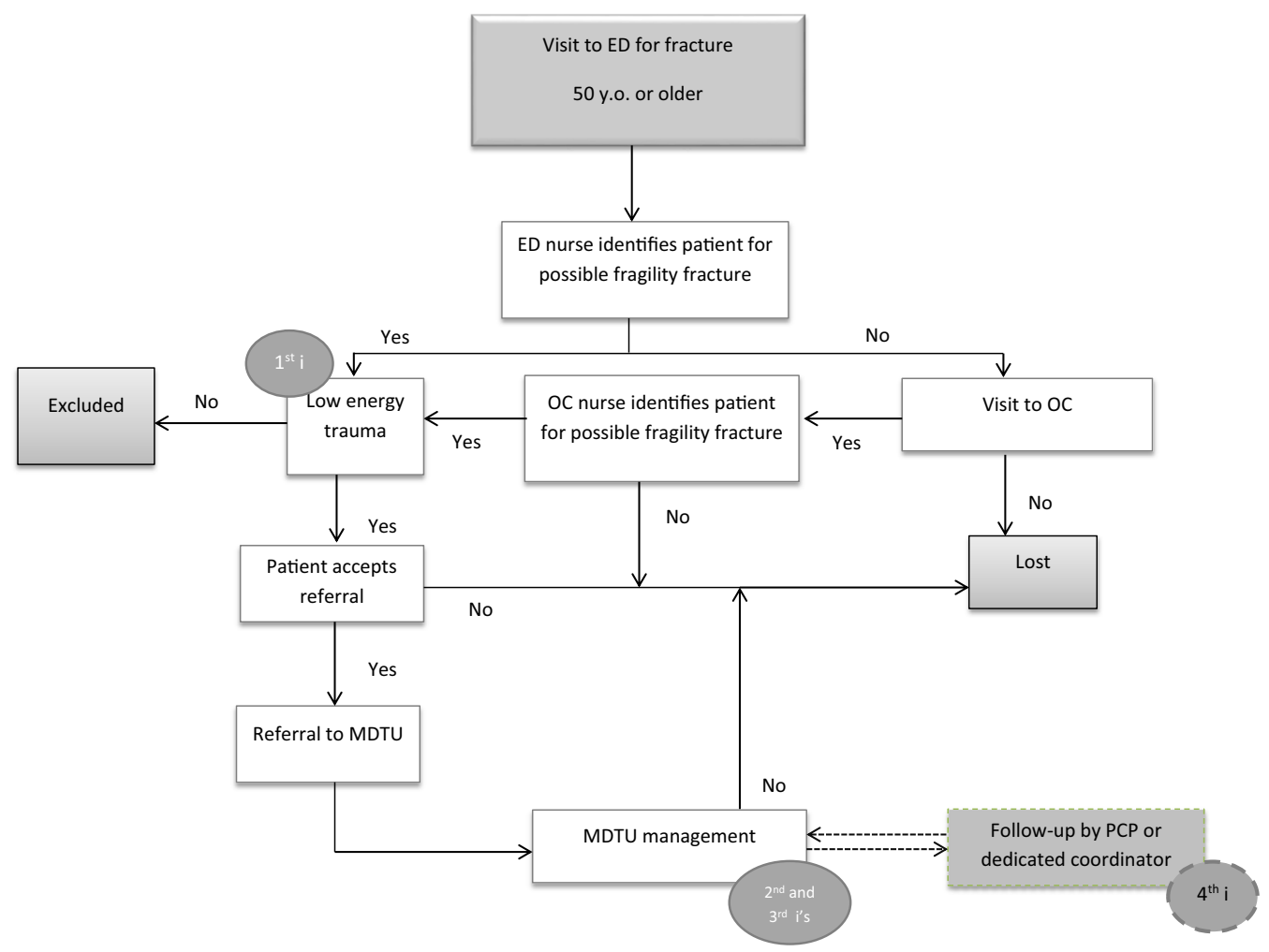

(ED) Emergency department, (MDTU) Medical Day Treatment unit, (OC) orthopaedic outpatient clinic, (PCP) primary care physician, (y.o.) year old

Fig. 1 Order set identification of fragility fracture patient process

fragility fractures, bone turnover, available treatments, fracture liaison service, management algorithm. ED/OC nurses attended a 1-h condensed theoretical teaching on the same modules.

Hip fractures were not included in this analysis, since this task was done on the orthopaedic ward (OW) where hospitalization allowed for dedicated management by the nursing staff. It is to be noted that a high volume of hip fractures is seen in our hospital as it is a centre of reference for hip fractures and that there is no walk-in clinic for non-hip, non-vertebral fractures.

\section{Study design}

We conducted a retrospective observational study. After staff training and a trial implementation to solve teething issues, the identification of patients started on November 2014. We retrieved the list of patients that visited the emergency department with a primary code of fracture for the period of November 2014 to July 2015. We isolated fracture patients of 50 years or older and had their medical files reviewed by the research coordinator to determine the mechanism of injury. High energy trauma fractures (motor vehicle accident, high velocity bicycle accident, fall from significant height, etc.) were excluded as well as fractures of bones beyond the neck, wrists and ankles. Hip fractures were also excluded from the analysis since their management was done by the staff not covered by the order set.

The remaining fractures were considered as our total number of fragility fractures, which was used as the denominator for the calculation of rate of identification (first i) (number of patients referred to the MDTU as numerator). The rate of management (second $i$ and third i) was obtained with the ratio of patients that agreed to be followed in the program over the number of patients referred to the MDTU. Statistics are mostly descriptive. Using Chi-square test and a Wilcoxon test for categorical (gender, type of fracture) and continuous (age) variables respectively, we compared (1) identified and missed patients during the identification process and (2) managed and refusal patients. We also looked graphically into the distribution of identification through the 9-month period. Statistical analysis was performed with SPSS Statistics version 22.0 (IBM Corp., Armonyk, NY, USA, 2013). We considered a $p$ value of $\leq 0.05$ as statistically significant.

Finally, nurses in charge of identification of fragility fractures answered an in-house questionnaire and commented on the program. They were asked if they found the identification process difficult to perform, if identification criteria were difficult to assimilate and 
Fig. 2 Nine-month identification and management chart

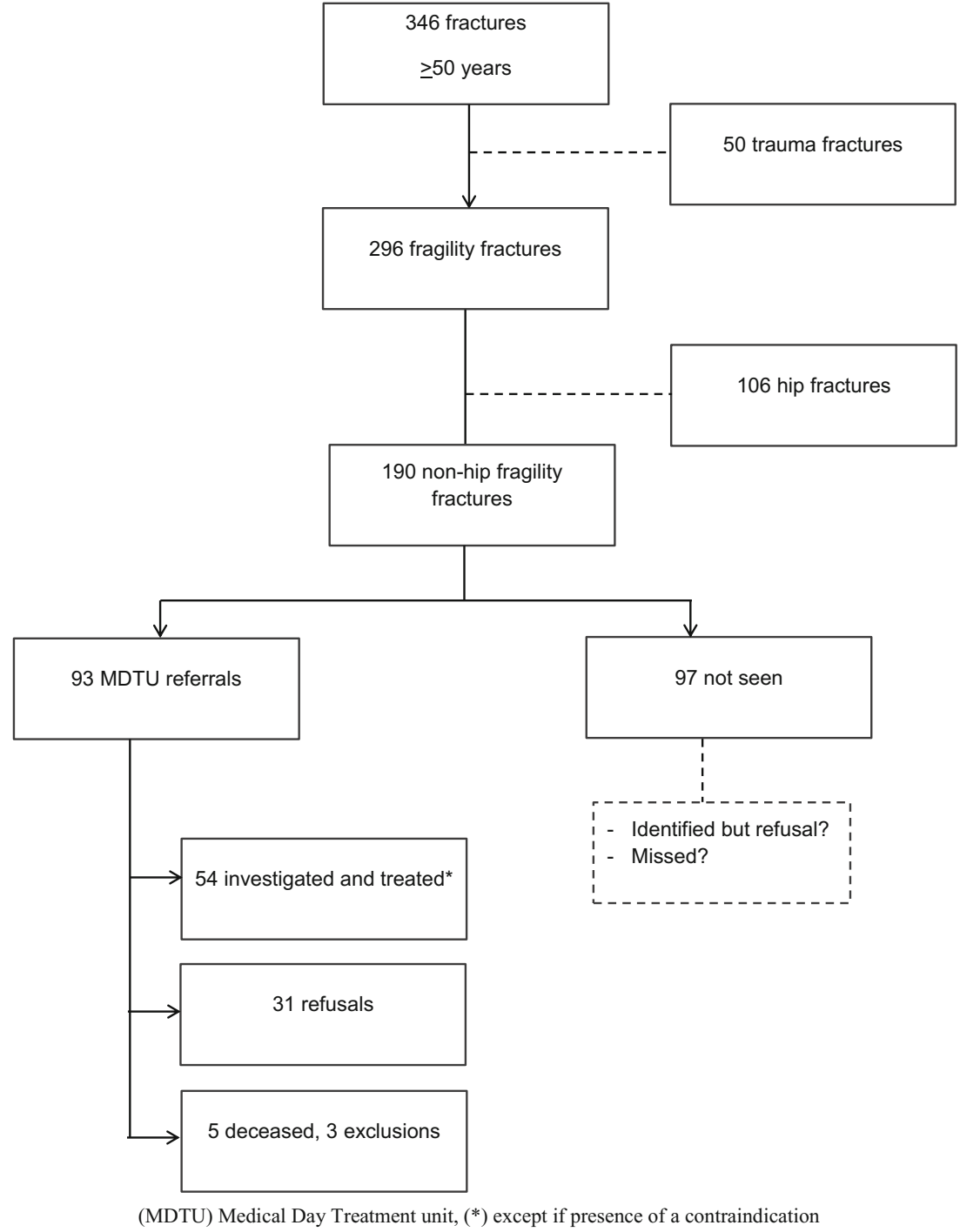

remember, if they had good knowledge on osteoporosis and if they could perform the identification task independently or if they needed supervision, feedback or more training. They answered according to the following groups of difficulty: (1) none, (2) low, (3) moderate, (4) high, (5) major, (6) no answer/never performed. These
Table 1 Identified vs. missed patients and managed vs. refusing patients according to age, gender and fracture site

\begin{tabular}{|c|c|c|c|c|c|c|}
\hline & \multicolumn{3}{|c|}{ Identification } & \multicolumn{3}{|c|}{ Management } \\
\hline & ID & Missed & $p$ & Managed & Refusal & $p$ \\
\hline$n$ & 93 & 97 & & 54 & 31 & \\
\hline Age, median(IR) & $72(21.5)$ & $71(22.5)$ & 0.678 & $71.5(19.3)$ & $68(28)$ & 0.844 \\
\hline Gender, $n$ female $(\%)$ & $70(75.3)$ & $73(75.3)$ & 0.999 & $38(70.4)$ & $26(83.9)$ & 0.165 \\
\hline \multicolumn{7}{|l|}{ Fracture site, $n(\%)$} \\
\hline Wrist & $22(23.7)$ & $24(24.7)$ & 0.002 & $14(25.9)$ & $8(25.8)$ & 0.461 \\
\hline Humerus & $32(34.4)$ & $12(12.4)$ & & $22(40.7)$ & $8(25.8)$ & \\
\hline Ankle & $10(10.8)$ & $20(20.6)$ & & $6(11.1)$ & $4(12.9)$ & \\
\hline Other & $29(31.2)$ & $41(42.3)$ & & $12(22.2)$ & $11(35.5)$ & \\
\hline
\end{tabular}

$I D$ identified patients, $I R$ interquartile range 
Table 2 Number and proportion of patients regarding non-hip fragility fractures identified and missed on a 9-month period

\begin{tabular}{lllll}
\hline Months & FF & ID & Missed & \% NH FF ID \\
\hline November & 25 & 17 & 8 & 68.0 \\
December & 32 & 14 & 18 & 43.8 \\
January & 31 & 18 & 13 & 58.1 \\
February & 16 & 6 & 10 & 37.5 \\
March & 33 & 19 & 14 & 57.6 \\
April & 10 & 6 & 4 & 60.0 \\
May & 12 & 4 & 8 & 33.3 \\
June & 14 & 5 & 9 & 35.7 \\
July & 17 & 4 & 13 & 23.5 \\
\hline
\end{tabular}

$F F$ fragility fractures, $I D$ identified patients, $N H$ non-hip

categories were regrouped under four to facilitate interpretation (none/low, moderate, high/major, no answer/never performed).

\section{Results}

A total of 346 patients $\geq 50$ years old $(71.1 \%$ females aged $74.6 \pm 13.6$ years) were diagnosed with a fracture between November 2014 and July 2015, according to the medicoadministrative database of the hospital. Of these 346 patients, 296 (74.3\% female) fulfilled the criteria for a fragility fracture after revision of medical files. This corresponds to $85.5 \%$ of all fracture patients of 50 years and older. The proportion of hip fractures within the fragility fractures cohort was of $35.8 \%(n=106)$.

\section{First "i"-identification of patients}

Figure 2 illustrates identification and management flow chart. Fractures not meeting the fragility criteria were excluded (14.4\%). From 190 non-hip fragility fractures,
93 patients were identified by the ED and/or the OC nurses and referred to the MDTU over a 9-month period.

Identified and missed patients are compared in Table 1. Fractures of the humerus were significantly more identified and referred to the MDTU compared to other sites $(p=0.002)$. Table 2 shows the proportion of identified patients per month. Figure 3 shows the distribution curve of identified patients' proportions per month. Over the 9-month period, identification ratios reached a maximum of almost $70 \%$ and a minimum near $30 \%$, varying heterogeneously through time. Figure 4 compares fracture sites in identified versus missed patients. For instance, out of the nine vertebral fractures, three were identified and managed.

\section{Second and third "i" - management of patients}

Out of the 93 identified and referred patients, 31 refused their appointment with the MDTU nurse $(33.3 \%)$ and 5 patients died $(5.4 \%)$. Three out of the five deceased were managed immediately by internal medicine at their arrival to the emergency department. Although we were called upon to deal with the fractures, two humeral necks and one tibial-peroneal, they died of severe comorbidities during hospitalization (heart attack, leukaemia and pneumonia). They were all aged 85 years or more. A fourth patient, with vertebral fracture, died less than a month after discharge from a pulmonary neoplasia. This leaves us with one patient, with a humeral neck fracture, who passed away a few months after the fracture from an unknown cause; we were not able to reach him in the meantime (social workers, FLS coordinators, etc.).

After a second assessment by MDTU nurses, three were excluded because the fracture did not meet the fragility criterion $(3.2 \%)$. This left 54 of the referred patients $(58.1 \%)$ managed by the MDTU nurses. Patients that agreed to be followed and those that refused are compared in Table 1 . Overall, the total proportion of patients managed by the MDTU nurses was of $28.4 \%(54 / 190)$.
Fig. 3 Distribution of proportion of identified patients between November 2014 and July 2015

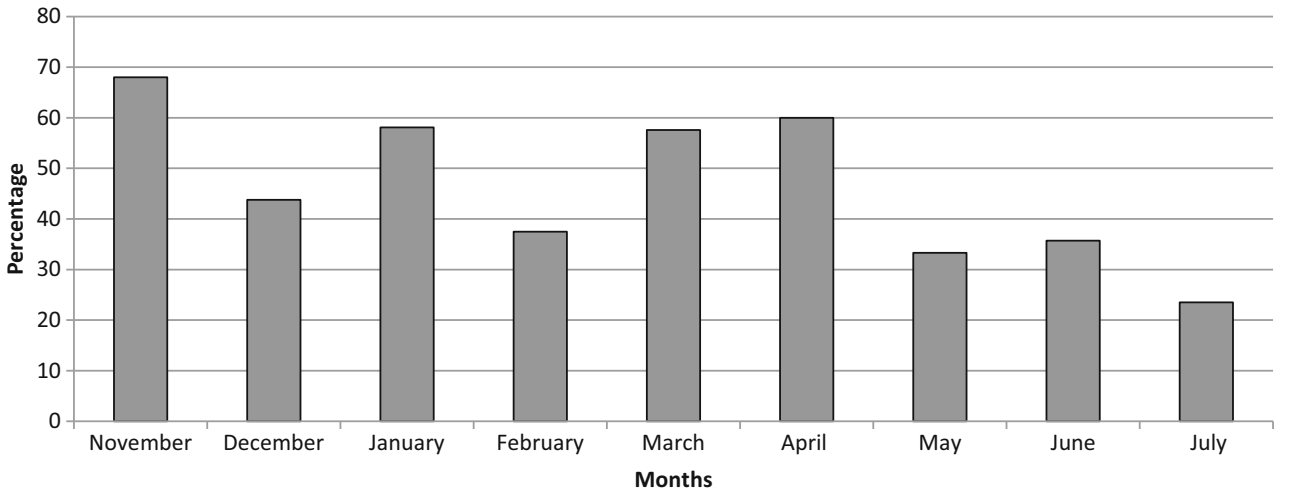


Fig. 4 Identified vs. missed patients for fracture site distribution

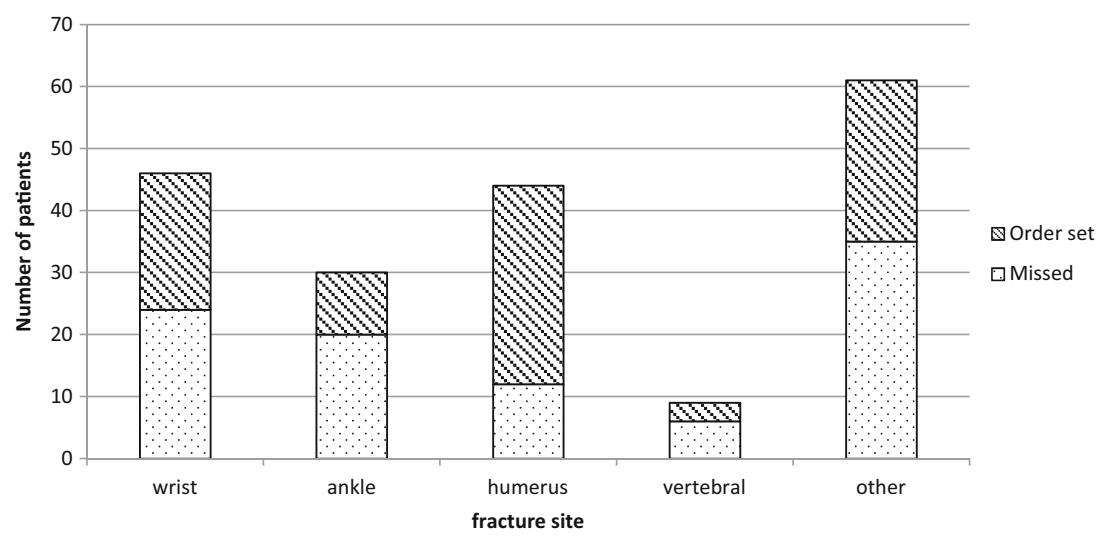

\section{In-house questionnaire on identification process}

Table 3 presents the results of the in-house questionnaires. Response rate was $50 \%(3 / 6)$ for OC nurses and $20.4 \%$ (11/45) for ED nurses. Two OC nurses out of three had no/ mild difficulty with time allocation, identification criteria, knowledge on the disease but would have appreciated more feedback. The other nurse found time-consuming the identification process and thought he/she could manage independently this task. Even if a majority of ED nurses had no/mild difficulty with the identification criteria, time allocation and knowledge on the disease were more challenging. Seven out of 11 nurses wanted supervision, feedback and more training. Comments were repetitive of questionnaire answers.

\section{Discussion}

An order set was issued on February 2014, legally empowering nurses to manage by themselves fragility fracture patients in a hospital. The present study assessed the impact of the program on the identification and management of patients. Our results show that when the order set was applied, a rate of identification of $70 \%$ could be reached (Fig. 3). When looking at studies on FLS, identification ratios varied between 40 and $90 \%$, a variability similar to our 30-70\% rates over time. However, FLS with dedicated management have identifications rates mostly neighbouring $80 \%$ [22-27]. Our rates varied through time mainly because of staff turnover and difficulty to integrate this new care to routine practice. The period of February to April 2015 was marked with a significant increase in the identification process, followed by an important decrease. In February 2015, the FLS coordinator gathered preliminary data to present during a 15-min informative session to ED and OC nurses. Data showed the decreasing identification performance over time. The coordinator reminded them of the importance to refer fragility patients to a secondary prevention service, of the reminder sheets with fragility criteria available in their work environment and of how the identification of fragility fractures can be performed very rapidly. This feedback had a positive impact on nurses in further identifying patients back to a $70 \%$ rate. Thus, a simple temporary retroactive action from a coordinator leads to significant performance improvement until it becomes part of routine practice and mindset. An electronic order set instead of a paper-form one could also have helped the identification and

Table 3 In-house questionnaire on order set progress - answers from OC and ED nurses

\begin{tabular}{|c|c|c|c|c|c|c|c|c|}
\hline \multirow{3}{*}{$\begin{array}{l}\text { Departments } \\
n \\
\text { Answer categories }\end{array}$} & \multicolumn{4}{|l|}{$\mathrm{OC}$} & \multicolumn{4}{|l|}{ ED } \\
\hline & \multicolumn{4}{|l|}{3} & \multicolumn{4}{|l|}{11} \\
\hline & $\begin{array}{l}\text { No/mild } \\
\text { difficulty }\end{array}$ & $\begin{array}{l}\text { Moderate } \\
\text { difficulty }\end{array}$ & $\begin{array}{l}\text { High/major } \\
\text { difficulty }\end{array}$ & $\begin{array}{l}\text { No answer/never } \\
\text { performed }\end{array}$ & $\begin{array}{l}\text { No/mild } \\
\text { difficulty }\end{array}$ & $\begin{array}{l}\text { Moderate } \\
\text { difficulty }\end{array}$ & $\begin{array}{l}\text { High/major } \\
\text { difficulty }\end{array}$ & $\begin{array}{l}\text { No answer/never } \\
\text { performed }\end{array}$ \\
\hline $\begin{array}{l}\text { 1. Allocated time to } \\
\text { identification }\end{array}$ & 2 & 0 & 1 & 0 & 5 & 1 & 3 & 2 \\
\hline $\begin{array}{l}\text { 2. Identification } \\
\text { criteria }\end{array}$ & 3 & 0 & 0 & 0 & 9 & 1 & 0 & 1 \\
\hline $\begin{array}{l}\text { 3. Knowledge on } \\
\text { osteoporosis }\end{array}$ & 3 & 0 & 0 & 0 & 6 & 4 & 1 & 0 \\
\hline $\begin{array}{l}\text { 4. Independent } \\
\text { management }\end{array}$ & 1 & & 2 & 0 & 3 & & 7 & 1 \\
\hline
\end{tabular}

$O C$ orthopaedic clinic, $E D$ emergency department 
referral. We are in the process of transitioning the paper order set into an electronic "pop-up" during emergency registration to make identification and referral mandatory during triage.

Approximately 20 to $30 \%$ of fragility fractures are properly managed worldwide, with a ratio of treatment considerably lower than that $[1,12,28-30]$. Our overall management ratio was of $58 \%$ when patients were referred to the MDTU, which demonstrates an important increase in management rate.

The in-house questionnaire answered by $11 \mathrm{ED}$ nurses and $3 \mathrm{OC}$ nurses was meant to understand lapses in identification of fragility fractures. Comments from nurses were unanimous on two subjects; they wanted more training and feedback. Only 1 out of 14 nurses thought no supervision was needed, nor feedback, and that the program was time-consuming. These results suggest that one training in the beginning of the program is not sufficient to yield the appropriate level of education in our professionals and that the temporary implication of a dedicated stakeholder, not necessarily as a supervisor, is important to give feedback and answer nurses' interrogations until this new type of care is integrated into routine practice.

An opinion paper published in 2013 overviewed the implementation of an FLS. The authors recommended standardizing care with order sets to improve the "capture" of fragility fractures [31]. They, and others, also indicated that one of the biggest challenges resides in funding [15, 31, 32]. An important strength of using our model of implementation consisted in the use of personnel already in place in the hospital. Most of FLSs use dedicated personnel to run their program [33, 34]. Our results show that it is possible to sustain such a service with staff nurses already on the payroll. This system was favoured by the division of tasks through separate departments. The service was also functional without the involvement of a bone champion physician, which contributed largely to decrease the associated costs. These results suggest the following implications: (1) the actual staff can work as FLS managers without hiring supplementary personnel and (2) nurses would substitute physicians for most screening and follow-up visits, thus reducing the direct cost of honorarium, and (3) an FLS nurse coordinator would be called upon only for abnormal screenings and could thus be freed to supervise several FLS programs at a time.

It is clear that our approach has some advantages: it lessens the burden of fragility fractures' management on the FLS manager, it incorporates a standard of practice (SOP) mindset on the management of fragility fractures, it frees ED doctors and orthopaedic surgeons to manage more complicated cases, it makes a better business case for fragility fracture implementation by relying on staff nurses instead of a dedicated FLS nurse and it could potentially lower the direct cost of fragility fracture management by substituting a fee-for-service billing by a fixed salary service provider.
We also identified points that needed improvement at the end of this study; the order set should be seen as the best clinical practice for the institutional policy towards fragility fractures, and an opting-out approach should be implemented accordingly. Printed or electronic charts should include the order set as a routine algorithm to be applied to all fracture cases. As it stands now, this model of care would still need an FLS manager in the background for quality control and managerial issues. The identification and training of a manager within the supervising staff could provide for a transition mode from FLS to a full independent fragility fracture SOP. We also noticed a denial on the patients and close relatives' part on the underlying osteoporosis, with a refusal to start investigation and treatment. It is beyond the scope of this study to analyse causes and propose solutions to this fact, but the general public and the patient's education on osteoporosis prevention and treatment must be addressed by public authorities and related bodies.

Our study has limitations. Firstly, the order set was not yet implemented on the wards due to staff changes. Therefore, the planned identification of hip fractures by the assistant head nurse had to be done by the FLS coordinator, leaving these fractures out of the analysis. We have not performed an economic analysis of the costs and benefits of our approach, thus we can only speculate on its financial impact for the healthcare provider. Lastly, we do not have any data on the management of patients for fragility fractures prior to the implementation of our FLS in this institution. Thus, we can only refer to comparable data and literature to determine if the order set allowed for a better performance towards the management of fragility fractures.

\section{Conclusion}

In conclusion, the issuance of a standardized order set for the management of osteoporosis-related fractures was found to increase their identification and management over a 9-month period, largely exceeding that of standard of care. However, the level of implication of the staff must be improved, especially for the first "i." Our experience suggests that an FLS can be functional with the staff already in place in hospitals, but that a clear hospital policy, adequate training, pre-printed or electronic algorithms and periodical feedback are essential for its success. This role could be assigned to a nursing administrator or a multirole FLS manager.

Acknowledgments We would like to thank Mrs. Liza O'Doherty, former Director of Nursing of the CSSS du Coeur-de-L'île, for making possible the implementation of this program.

Compliance with ethical standards All procedures performed in this study involving human participants were in accordance with the ethical standards of the Hôpital Sacré-Coeur de Montréal and Centre Hospitalier 
de l'Université de Montréal ethic research committees and with the 1964 Helsinki Declaration and its later amendments or comparable ethical standards.

Conflicts of interest Dr. Julio C Fernandes, Ms. Andréa Senay, Ms. Josée Delisle, Dr. Mario Giroux, Dr. G Yves Laflamme, Dr. Stephane Leduc, Dr. Michel Malo, Dr. Hai Nguyen, Dr. Pierre Ranger report grants from Eli Lilly during the conduct of this study. Ms. Josée Delisle also reports support for personal fees from Amgen Canada and Eli Lilly outside of the conducted work. Dr. G Yves Laflamme reports research grants from Zimmer, Stryker and DePuy Synthes, and support as a consultant from Stryker outside of the conducted work. Dr. Stephane Leduc reports research grants from Stryker, DePuy Synthes, Smith \& Nephew and Zimmer, and support as a consultant from Stryker outside of the conducted work. Dr. Pierre Ranger reports grants from Johnson \& Johnson, support as a consultant from Smith \& Nephew, Corin, Bioventus, Sanofi Canada, and support for development of educational presentations by Horizon Pharma outside of the conducted work. Dr. Julio C Fernandes reports unrestricted educational grants from Amgen, Novartis, Sanofi and Boehringer Ingelheim and grants from Baxter outside of the conducted work.

Open Access This article is distributed under the terms of the Creative Commons Attribution-NonCommercial 4.0 International License (http:// creativecommons.org/licenses/by-nc/4.0/), which permits any noncommercial use, distribution, and reproduction in any medium, provided you give appropriate credit to the original author(s) and the source, provide a link to the Creative Commons license, and indicate if changes were made.

\section{References}

1. Scientific Advisory Board of the European Society for Clinical and Economic Aspects of Osteoporosis and Osteoarthritis (ESCEO) and the Committee of Scientific Advisors of the International Osteoporosis Foundation (IOF), Kanis JA, McCloskey EV, Johansson H, Cooper C, Rizzoli R, Reginster JY (2013) European guidance for the diagnosis and management of osteoporosis in postmenopausal women. Osteoporos Int 24(1):23-57. doi:10.1007 /s00198-012-2074-y

2. Cauley JA (2013) Public health impact of osteoporosis. J Gerontol A Biol Sci Med Sci 68(10):1243-1251. doi:10.1093/gerona/glt093

3. Bertram M, Norman R, Kemp L, Vos T (2011) Review of the longterm disability associated with hip fractures. Inj Prev 17(6):365370. doi:10.1136/ip.2010.029579

4. Leslie WD, O'Donnell S, Lagacé C, Walsh P, Bancej C, Jean S et al (2010) Population-based Canadian hip fracture rates with international comparisons. Osteoporos Int 21(8):1317-1322. doi:10.1007 /s00198-009-1080-1

5. Haentjens P, Magaziner J, Colon-Emeric CS, Vanderschueren D, Milisen K, Velkeniers B et al (2010) Meta-analysis: excess mortality after hip fracture among older women and men. Ann Intern Med 152(6):380-390

6. Bliuc D, Nguyen ND, Nguyen TV, Eisman JA, Center JR (2013) Compound risk of high mortality following osteoporotic fracture and refracture in elderly women and men. J Bone Miner Res 28: 2317-2324

7. Tarride JE, Hopkins RB, Leslie WD, Morin S, Adachi JD, Papaioannou A et al (2012) The burden of illness of osteoporosis in Canada. Osteoporos Int 23(11):2591-2600. doi:10.1007 /s00198-012-1931-z
8. Burge R, Dawson-Hughes B, Solomon DH, Wong JB, King A, Tosteson A (2007) Incidence and economic burden of osteoporosis-related fractures in the United States, 2005-2025. J Bone Miner Res 22(3):465-475

9. Hernlund E, Svedbom A, Ivergård M, Compston J, Cooper C, Stenmark J et al (2013) Osteoporosis in the European Union: medical management, epidemiology and economic burden. A report prepared in collaboration with the International Osteoporosis Foundation (IOF) and the European Federation of Pharmaceutical Industry Associations (EFPIA). Arch Osteoporos 8:136. doi:10.1007/s11657-013-0136-1

10. Maraka S, Kennel KA (2015) Bisphosphonates for the prevention and treatment of osteoporosis. BMJ 351:h3783. doi:10.1136/bmj. h3783

11. Bolland MJ, Grey AB, Gamble GD, Reid IR (2010) Effect of osteoporosis treatment on mortality: a meta-analysis. J Clin Endocrinol Metab 95(3):1174-1181

12. Aizer J, Bolster MB (2014) Fracture liaison services: promoting enhanced bone health care. Curr Rheumatol Rep 16(11):455. doi:10.1007/s11926-014-0455-2

13. Javaid MK, Kyer C, Mitchell PJ, Chana J, Moss C, Edwards MH et al (2015) Effective secondary fracture prevention: implementation of a global benchmarking of clinical quality using the IOF Capture the Fracture ${ }^{\circ}$ Best Practice Framework tool. Osteoporos Int 26(11): 2573-2578. doi:10.1007/s00198-015-3192-0

14. Akesson K, Marsh D, Mitchell PJ, McLellan AR, Stenmark J, Pierroz DD et al (2013) Capture the Fracture: a best practice framework and global campaign to break the fragility fracture cycle. Osteoporos Int 24(8):2135-2152. doi:10.1007/s00198-013-2348-Z

15. Eisman JA, Bogoch ER, Dell R, Harrington JT, McKinney RE Jr, McLellan A et al (2012) Making the first fracture the last fracture: ASBMR task force report on secondary fracture prevention. J Bone Miner Res 27(10):2039-2046

16. Senay A, Delisle J, Raynauld JP, Morin SN, Fernandes JC (2015) Agreement between physicians' and nurses' clinical decisions for the management of the fracture liaison service (4iFLS): the Lucky Bone ${ }^{\mathrm{TM}}$ program. Osteoporos Int

17. Healthcare Human Factors, University Health Work (2009) Order sets in healthcare: an evidence-based analysis. Toronto, Canada. $\mathrm{http} / / /$ ehealthinnovation.org/wp-content/uploads/Patient-OrderSets_Report_OHTAC_UHNHHF_Feb_10_Final.pdf. Accessed 11 Aug 2015

18. Civil code of Québec (2014) Nurse Act. Québec, Canada. http://www2.publicationsduquebec.gouv.qc. $\mathrm{ca} /$ dynamicSearch/telecharge.php?type=2\&file=/I_8/I8_A.html. Accessed 11 Aug 2015

19. Papaioannou A, Morin S, Cheung AM, Atkinson S, Brown JP, Feldman S et al (2010) 2010 clinical practice guidelines for the diagnosis and management of osteoporosis in Canada: summary. CMAJ 182(17):1864-1873. doi:10.1503/cmaj.100771

20. Brown JP, Josse RG (2002) 2002 clinical practice guidelines for the diagnosis and management of osteoporosis in Canada. CMAJ 167(10 Suppl):S1-S34

21. Kanis JA, Oden A, Johansson H, Borgström F, Ström O, McCloskey E (2009) FRAX and its applications to clinical practice. Bone 44(5):734-743. doi:10.1016/j.bone.2009.01.373

22. Dehamchia-Rehailia N, Ursu D, Henry-Desailly I, Fardellone P, Paccou J (2014) Secondary prevention of osteoporotic fractures: evaluation of the Amiens University Hospital's fracture liaison service between January 2010 and December 2011. Osteoporos Int 25(10):2409-2416. doi:10.1007/s00198-014-2774-6

23. Eekman DA, van Helden SH, Huisman AM, Verhaar HJ, Bultink IE, Geusens PP et al (2014) Optimizing fracture prevention: the fracture liaison service, an observational study. Osteoporos Int 25(2):701-709. doi:10.1007/s00198-013-2481-8 
24. Vaile JH, Sullivan L, Connor D, Bleasel JF (2013) A year of fractures: a snapshot analysis of the logistics, problems and outcomes of a hospital-based fracture liaison service. Osteoporos Int 24(10): 2619-2625. doi:10.1007/s00198-013-2357-y

25. Lih A, Nandapalan H, Kim M, Yap C, Lee P, Ganda K et al (2011) Targeted intervention reduces refracture rates in patients with incident non-vertebral osteoporotic fractures: a 4-year prospective controlled study. Osteoporos Int 22(3):849-858. doi:10.1007/s00198$010-1477-x$

26. Ojeda-Bruno S, Naranjo A, Francisco-Hernández F, Erausquin C, RúaFigueroa I, Quevedo JC et al (2011) Secondary prevention program for osteoporotic fractures and long-term adherence to bisphosphonates. Osteoporos Int 22(6):1821-1828. doi:10.1007/s00198-010-1414-z

27. Harrington JT, Lease J (2007) Osteoporosis disease management for fragility fracture patients: new understandings based on three years' experience with an osteoporosis care service. Arthritis Rheum 57(8):1502-1506

28. Fraser LA, Ioannidis G, Adachi JD, Pickard L, Kaiser SM, Prior J et al (2011) Fragility fractures and the osteoporosis care gap in women: the Canadian Multicentre Osteoporosis Study. Osteoporos Int 22(3):789796. doi:10.1007/s00198-010-1359-2
29. Bessette L, Ste-Marie LG, Jean S, Davison KS, Beaulieu M, Baranci M et al (2008) The care gap in diagnosis and treatment of women with a fragility fracture. Osteoporos Int 19(1):79-86

30. Giangregorio L, Papaioannou A, Cranney A, Zytaruk N, Adachi JD (2006) Fragility fractures and the osteoporosis care gap: an international phenomenon. Semin Arthritis Rheum 35(5):293-305

31. Curtis JR, Silverman SL (2013) Commentary: the five Ws of a fracture liaison service: why, who, what, where, and how? In osteoporosis, we reap what we sow. Curr Osteoporos Rep 11(4):365368. doi:10.1007/s11914-013-0177-9

32. Jaglal SB, Donescu OS, Bansod V, Laprade J, Thorpe K, Hawker G et al (2012) Impact of a centralized osteoporosis coordinator on post-fracture osteoporosis management: a cluster randomized trial. Osteoporos Int 23(1):87-95. doi:10.1007/s00198-011-1726-7

33. Miller AN, Lake AF, Emory CL (2015) Establishing a fracture liaison service: an orthopaedic approach. J Bone Joint Surg Am 97(8):675-681. doi:10.2106/JBJS.N.00957

34. Sale JE, Beaton D, Posen J, Elliot-Gibson V, Bogoch E (2011) Systematic review on interventions to improve osteoporosis investigation and treatment in fragility fracture patients. Osteoporos Int 22:2067-2082 